\title{
An Integrated Model of Pro-Poor Innovation Adoption Within the Bottom of the Pyramid: An Abstract
}

\author{
Rajib Hasan, Ben Lowe, and Dan Petrovici
}

\begin{abstract}
Both for-profit and non-profit/NGO/social businesses may target bottomof-the-pyramid (BOP) consumers as potential new market segments and to better serve the needs of this often neglected group of consumers. Research on BOP consumers has attracted considerable attention recently. Despite financial constraints, BOP consumers have been seen to be adopters of innovations which enhance their well-being - these are often known as pro-poor innovations.

However, very little is known about how such consumers adopt innovations with the majority of innovation adoption research conducted in wealthier economically more advanced economies. To understand the antecedents of innovation adoption in the BOP, this research contributes to the literature by developing an integrated model of pro-poor innovation adoption for use within the BOP. It does this by identifying and empirically comparing existing and widely cited models in the context of a BOP market, with a survey conducted in Bangladesh, and then using these results, along with theory in the area, derives the new integrated model. The new model is validated using a new product category and sample.

The findings from this research provide valuable theoretical and practical guidance to academics and managers on the key antecedents of pro-poor innovation adoption within the BOP.
\end{abstract}

R. Hasan

ESC Rennes, Rennes, France

e-mail: rajib.nsu.051@gmail.com

B. Lowe $(\bowtie) \bullet$ D. Petrovici

University of Kent, Canterbury, UK

e-mail: b.lowe@kent.ac.uk; d.a.petrovici@kent.ac.uk 